\title{
Investigation on the Feasibility of Integrating Chinese Culture into Teaching Chinese as a Foreign Language
}

\author{
Wei Pei Ling ${ }^{1 *}$, Zhu Yong Fei ${ }^{2}$, Li Wensi ${ }^{3}$ \\ ${ }^{I}$ Department of Public Administration, Nan fang College of Sun Yat-sen University, Guangzhou, Guangdong, 510000, \\ China \\ ${ }^{2}$ Department of Public Administration, Nan fang College of Sun Yat-sen University, Guangzhou, Guangdong, 510000, \\ China \\ ${ }^{3}$ Department of Public Administration, Nan fang College of Sun Yat-sen University, Guangzhou, Guangdong, 510000, \\ China
}

*Corresponding author's e-mail: penny343@163.com

\begin{abstract}
In this study, teachers and Chinese learners of Chinese schools in the United States are taken as the research objects, and Chinese cultural symbols are used as the main design axis for teaching experiments. The research focuses on the feedback results of overseas Chinese teachers and learners in non-target language environment, the real needs of cultural teaching and learning, and combs the multi-cultural perspective of teaching Chinese as a foreign language to improve the effect of culture teaching in the future.
\end{abstract}

Keywords: Teaching Chinese as a foreign language, feasibility, cultural symbols, cultural map

\section{PREFACE}

Cultural teaching contents required by overseas Chinese teaching. Due to the fact that Chinese culture teaching is not the mainstream in the field of teaching Chinese as a foreign language, there are few researchers. In addition, the culture textbook was originally written to strengthen overseas Chinese learners' recognition of the motherland. For Chinese learners born in non target language environment, due to the lack of cultural context, cultural identity and cultural atmosphere, the course content is suitable for Chinese learners growing up in the American cultural environment. In other words, there are difficulties in cross-cultural understanding both in literal narration and in cultural value.

In view of this, 16 senior overseas Chinese teachers with teaching experience in Chinese culture courses and 34 Chinese learners in non-target language environment were selected as the research objects in this study. The perspective of users and learners in overseas culture textbooks was taken as the demand orientation, and the demand points of overseas Chinese culture teaching were sorted out and analyzed as the direction of future overseas Chinese culture teaching plan compilation.

\section{Literature review}

The importance of integrating Chinese culture into teaching Chinese as a foreign language can be illustrated by the two directions of the United States and China. In the United States, in 2003, AP Chinese curriculum promoted the development of AP Chinese education in the United States, and teaching in overseas Chinese schools also cooperated with the new teaching indicators of $5 \mathrm{C}$ communication orientation (Jiang Ximei, 2009)

In China, Ma Jianfei (2004) mentioned that the teaching principle and teaching method trend of "structure,function and culture" began in the 1980s. Chinese teaching should be "structure-based, function oriented and cultural integration".

As Zhu Ruiping (2008) said,early foreign language teaching emphasized only the teaching of language skills rather than "culture". Until the cultural issues gradually gained attention, more and more people believed that "culture" was not only a single ability, but should run through all kinds of language abilities when learning a foreign language.This is the basic concept of AP spirit that takes culture as the main teaching axis, It is hoped that in the process of language learning, students can constantly find the same or different ideas, customs and products with their own culture.

From a broad or narrow point of view, although language is not equal to culture, language and characters are carriers of culture. In fact, culture is a complex and dynamic composition structure, rather than a static state not associated with other majors. Chinese culture in teaching Chinese as a foreign language should not be limited to linguistics, but to help overseas Chinese learners use language as an extension tool to open up another new vision, such as aesthetics, sociology, history and other experiences into Chinese culture. This is also in line with Shen Xiaolong's (2000) proposal that "because language and human social behavior are integrated, language is the only way to produce, develop, inherit and obtain culture, so language can reflect the whole history, culture, games, entertainment, beliefs and prejudices of a nation in great detail." 


\section{Interview with overseas Chinese teachers}

Based on the views put forward by 16 senior overseas Chinese teachers with Chinese culture teaching experience, the author classifies them into two directions: viewpoint and feasible suggestions.

\subsection{Views of overseas Chinese teachers}

Overseas Chinese teachers believe that there are two problems in the teaching of Chinese culture courses

\subsubsection{The psychological process of overseas Chinese teachers with intercultural understanding}

There is no shortcut to the teaching of culture. Like most people, there is often cultural shock when they accept a new culture. Overseas Chinese teachers need to pay close attention to each other, design progressive courses, and cut into the cultural themes discussed in simple terms from different angles. Only in this way can non purposeful and environmental learners gradually understand and accept Chinese culture. However, there is still a lack of teacher training in this area.

\subsubsection{The connection between explicit culture and implicit culture}

In the process of interaction, Chinese learners in non target language environment will take the cultural experience or feeling as the carrier of understanding Chinese culture, especially the non-chinese learners of Chinese language Therefore, there should be a more detailed teaching process between the explicit culture and the implicit culture,so that the broad and profound Chinese cultural connotation can be smoothly transferred to the Chinese learners in the non-target language environment.

\subsection{Feasible suggestions for overseas Chinese teachers}

The suggestions of overseas Chinese teachers have three directions: cultural context, cultural vocabulary and cultural communication

The cultural and linguistic environment is an important basic condition for learning cross-cultural communication and expression ability. It is a necessary process for the non target language Chinese learners to understand the correct Chinese narration in a certain situation with the aid of visual aids. We should know that in real life, even in the same cultural context, the expressions of the same words may have different meanings for different countries or nationalities. Non target language Chinese learners can not only avoid cultural misunderstanding,but also accelerate memory by using appropriate vocabulary in the cultural context guided by overseas Chinese teachers.

Cultural vocabulary is the basis of cultural topic discussion. Language is for the sake of culture. Carrying out the keywords of the thinking in the direction of the cultural theme can not only improve the vocabulary. Different cultural themes can also link philology, culturology, history, anthropology, aesthetics and other extended learning related fields.

The dissemination of Chinese culture overseas is an important purpose of cultural courses in teaching Chinese as a foreign language. Considering the local conditions and local conditions from a macro perspective, planning short-term, medium-term and long-term project teaching of Chinese culture, and guide overseas Chinese teachers to use local landscape and overseas Chinese resources to open training courses in Chinese language culture for foreigners is the future trend and direction.

\section{Interviews with Chinese learners in non target language environment}

This study is based on the two overseas Chinese schools in North Carolina, USA.The author takes cultural symbols as the theme to carry out a Chinese culture teaching experiment combining language and culture. 34 learners, aged between 15-23 years old, are involved in the teaching experiment. Some of the learners are senior high school students who have taken AP Chinese examination, and some students are taking Chinese courses in universities The discussion is divided into two directions: viewpoint and feasible suggestion.

\subsection{Views of Chinese learners in non-target language environment}

\subsubsection{Chinese teachers' teaching style determines learners' willingness to learn}

In the non-target language environment, Chinese learners observe the differences between Chinese and American teachers. Chinese teachers prefer one-way output and pay attention to the four characteristics of Chinese culture: broad, large, refined and profound. Second language teachers in the United States do not attach importance to this macro concept in class, but emphasize student-centered autonomous learning process. This is because American second language teachers believe that if Chinese learners in non-target language environment do not have "engine" and "fun" to explore, they will gradually lose their curiosity about foreign culture, and it is difficult to continue their enthusiasm for learning.

Under the consideration of the direction of American education, Chinese learners in non-target language environment put forward the concepts of thinking direction that Chinese teachers need to master, difficulties in learning 
Chinese culture and thinking map for Chinese learners in non-target language environment.

In terms of the thinking direction hat Chinese teachers need to master, the Chinese learners interviewed in the non-target language environment said that the teaching situations in American schools and Chinese schools are very different. Generally speaking, there is a preference for one-way communication in Chinese class, while the classroom atmosphere of second foreign language in American schools focuses on multiple ways of interaction, communication and discussion, and proposes that Chinese culture teaching should be targeted at different situations. According to the needs of sensory learners, interesting activities should be designed to sustain learners' motivation. Chinese teachers can also use fun as a chip to master the class order and stimulate deeper learning motivation in learning.

\subsubsection{Chinese culture needs more visual media}

Chinese learners' difficulties in learning Chinese culture are related to their language learning habits. It is worth noting that Chinese learners in non-target language environment propose that "characters with the same pronunciation may have several different fonts or similar expressions in writing when learning Chinese. American learners are influenced by pinyin habits and their thinking is based on pronunciation to search for the closest word or word in their brains.

Therefore, when applied to Chinese learning, pronunciation errors often occur.For example, there is a link in the culture course, in which non-target language Chinese learners are asked to observe and prompt the pronunciation of "Shou" with the common cultural symbol "Shou $\mathrm{Zi} \mathrm{Wen",} \mathrm{which} \mathrm{is}$ a common cultural symbol in the art of tying rope, paper cutting and furniture of Ming Dynasty.The proportion of answers obtained is three kinds: the unbearable, the thin and the enjoying. The reason is that these three kinds of answers are in daily life The most often heard pronunciation, and do "Shou" in life never heard. However, when you take out the chopsticks cover with the word "Shou" printed on the Chinese restaurant in China Town, and compare it with the "longevity" pattern in the PPT,the learners can immediately combine with their life experience and quickly understand it.

\subsubsection{Applying mind map to Chinese Teaching}

Because Chinese is not like the phonetic characters of other languages, we can hear, read and write the characters according to the clues of pronunciation. Therefore, learners put forward the concept of mind map learning. For example, China is a "silk" nationality. Therefore, the radical "department" is the main part, and the related color, action and material characters are classified. With the help of video and pictures, students' understanding of the vocabulary is improved. Teaching feedback also shows that the speed of memorizing the series of characters has been significantly improved.

\subsection{Feasible suggestions for learners in non-target language environment}

\subsubsection{Fun is the most important factor in continuing learning}

For most of the non-target language learners, it is only when they have fun that they have the motivation to continue learning Chinese. The combination of language and culture through thematic cultural activities is a teaching method that can be developed in the future.

\subsubsection{Cultural learning of Chinese as a foreign language should be conducted from multiple perspectives}

(a) Put the evolution of "text" in the textbook and explain it in the form of images or cartoons.

(b) Strengthen the explanation and discrimination of the same sound in the culture course.

(c)Culture is narrated with stories, which is easier for students to accept.

(d) Pictures have explanation for imagination and are easier to remember.

(e) If you can see something in life in Chinese culture class, there are more topics to discuss.

(f) Increase the use and practice time of cultural vocabulary in textbooks

(g) Understanding of cultural works and sense of achievement of participation

\section{CONCLUSION}

The real world is a kaleidoscope world composed of complexity and dynamics. As mentioned above, a cultural theme contains different professional words, and different cultural themes can also link philology, culturology, history, anthropology, aesthetics, etc. These not only need Chinese as a carrier, but also can be appropriate according to the cultural environment of different regions and Chinese learners' learning tendency Adjust the best way of cultural communication. From the feedback from overseas Chinese teachers and Chinese learners in non target environment, it can be seen that the effective integration of "Chinese culture teaching" into "teaching Chinese as a foreign language" is not a simple integration of the two majors with $1+1=2$. Overseas Chinese teachers must understand "Chinese culture teaching", "Teaching Chinese as a foreign language" is like a spiral curve that needs to be repeated many times. In the teaching structure, it needs "rhythm" and "temperature" to trigger learning motivation and stimulate 
autonomous learning. The whole teaching process includes cultural teaching methods, the resolution of cultural stereotypes,cross-cultural communication, the understanding of cultural values and interdisciplinary integration Approach. There are quite a lot of books on the basis of Chinese culture, but there are few textbooks about cultural symbols and various cultural themes. The feasibility of integrating Chinese culture into teaching Chinese as a foreign language is that it does not need to be restricted by the language verification test, and the combination of cultural content is relatively free. How to make the cultural teaching materials or teaching methods meet the requirements of cultural context,cultural vocabulary and cultural communication will be the future The potential demand and opportunity of Chinese as a foreign language market.

\section{ACKNOWLEDGMENT}

This research was supported by colleagues and students in the School of Literature and Media, Nan fang College of Sun Yat-sen University. Thanks for their hard-working.

\section{REFERENCES}

[1] Cheng Tang (1992). Some problems in the current teaching of Chinese as a foreign language [J]. Language teaching and research: 14

[2] Jiang Ximei (2009). Principles of Chinese Language Teaching: how to teach children of overseas Chinese schools to learn Chinese [J]. Zhongyuan Chinese Journal 3: 43-53.

[3] Gao Songqiang (2006). On AP Chinese and the development of Chinese school. May 13, 2010, taken from http://forum.hopechinese.com/index.php?topic 。

[4] Ma Jianfei (2004). Methods of teaching Chinese as a foreign language $[\mathrm{M}]$. In Zhao Jinming (editor in chief). Introduction to teaching Chinese as a foreign language. Beijing: Business: 99-132.

[5] Shen Xiaolong (2000.1). Modern thinking of language and culture [M]. Zhengzhou: Henan people's Publishing House: 3-4.

[6] Wei Peiling (2017) practice and thinking of Chinese teaching culture curriculum. Linguistics and Chinese language 2 and teaching: curriculum and testing [M]. Commercial Press (Hong Kong) Co., Ltd., 2017.

[7] Zhu Ruiping (2008). Cultural considerations in AP Chinese and culture curriculum and examination design $[\mathrm{J}]$. Zhongyuan Chinese Journal, 2:29-30.
[8] Zhang Jinlan (2016). Patrick R. Moran: Teaching Culture: perspectives in practice book review [J]. Chinese language teaching research, 2016, 13 (2): 109-115. 